\title{
Management of the Spectrum of Essential Hypertension: A 2013 Perspective
}

\section{Cristian Riella and Theodore I Steinman*}

Department of Medicine, Nephrology Division, Beth Israel Deaconess Medical Center and Harvard Medical School, USA

\begin{abstract}
Management of hypertension: The association of hypertension with cardiovascular and renal disease is continuous and independent of other risk factors. Despite the increase in awareness and treatment of hypertension in the past decade, less than $50 \%$ of adults in the U.S have adequate blood pressure control. Every $10 \%$ increase in the treatment of patients with hypertension could prevent an additional 14,000 deaths. This article reviews the latest evidence guiding current hypertension management.

The main classes of drugs used to treat hypertension are diuretics (thiazides, loop and aldosterone antagonists), angiotensin converting enzyme inhibitors, angiotensin receptor blockers, calcium channel blockers, beta-blockers. Alpha-adrenergic blockers and direct renin inhibitors are used infrequently and are mostly used as the 4th or 5th added agent.

No consensus has been established on initial drug choice. In patients with compelling indications, such as ischemic heart disease, diabetes, chronic kidney disease and stroke, some classes have shown greater benefits. Widely accepted is that blood pressure reduction is the most important determinant in lowering cardiovascular risk when there is no indication for a particular class of drugs. Hypertensive patients with central and peripheral vascular disease, chronic kidney disease and diabetes should have a lower target blood pressure.

In patients with mild primary hypertension undergoing monotherapy, with inadequate blood pressure control, sequential monotherapy may be attempted prior to adding another drug. Combination therapy should be considered from the onset in individuals with blood pressures that exceed $20 / 10 \mathrm{mmHg}$ above the set target range.

The combination of angiotensin converting enzyme inhibitor plus a calcium channel blocker has been proven to be superior to other combinations. Considering the impact that adequate treatment can make in preventing deaths, the challenge is to improve access to care of patients with hypertension.
\end{abstract}

Keywords: Hypertension; Management of hypertension; High blood pressure; Cardiovascular risk; Chronic kidney disease prevention; Hypertension pharmacotherapy; Primary care; Diabetes; Drug choice in hypertension; Hypertension guidelines

\section{Introduction}

Despite the increase in awareness and treatment of hypertension in the past 10 years, less than $50 \%$ of adults in the U.S have adequate Blood Pressure (BP) control [1,2]. The age-adjusted prevalence of hypertension among adults in the U.S is estimated to be $28.6 \%$, which translates to over 50 million people affected by the disease [2]. The population aged 60 and over has an even higher prevalence of $66.7 \%$. Prediction models show that every $10 \%$ increase in the treatment of patients with hypertension, among the adult population, could prevent an additional 14,000 deaths [3].

\section{Classification}

The current classification of Blood Pressure (BP), as defined by the Seventh Report of the National Committee on Prevention, Detection, Evaluation, and Treatment of High Blood Pressure (JNC 7), is based on the average of three seated BP readings on at least three separate occasions at least one week apart [4]. In the last JNC report the prehypertension category was added, highlighting the increased risk of progression to hypertension in this group (Table 1). The association of blood pressure with cardiovascular (CV) and renal disease is continuous and independent of other risk factors [5-7]. Patients with a $\mathrm{BP}$ in the range of 130-139/80-89 $\mathrm{mmHg}$ have two times the risk of developing hypertension than those below this range [8]. Over 5 years the CV risk increases in a direct relationship with increasing Systolic Blood Pressure (SBP) [8].

\section{Obtaining accurate BP values}

Blood pressure should ideally be measured in a controlled, standardized fashion. Home measurements performed by the patient, 3 times a week, at different times of the day provide a more comprehensive method than spot measurements at a clinic visit. The patient should be instructed to utilize a calibrated, automated, upper arm cuff BP monitor, taking measurements while seated (for at least

*Corresponding author: Theodore I Steinman, Department of Medicine, Nephrology Division, Beth Israel Deaconess Medical Center and Harvard Medical School, 330 Brookline Ave., Boston, MA 02215, USA, Tel: 617-667-5278; Fax: 617975-5595; E-mail: tsteinma@bidmc.harvard.edu

Received June 19, 2013; Accepted August 29, 2013; Published September 05, 2013

Citation: Riella C, Steinman TI (2013) Management of the Spectrum of Essential Hypertension: A 2013 Perspective. Cardiol Pharmacol 2: 111. doi:10.4172/23296607.1000112

Copyright: (c) 2013 Riella C, et al. This is an open-access article distributed under the terms of the Creative Commons Attribution License, which permits unrestricted use, distribution, and reproduction in any medium, provided the original author and source are credited. 
Citation: Riella C, Steinman TI (2013) Management of the Spectrum of Essential Hypertension: A 2013 Perspective. Cardiol Pharmacol 2: 111. doi:10.4172/23296607.1000112

Page 2 of 7

\begin{tabular}{|c|c|c|c|c|}
\hline \multirow{2}{*}{ BP classification } & \multirow{2}{*}{$\begin{array}{l}\mathrm{SBP}^{*} \\
\mathrm{mmHg}\end{array}$} & \multirow{2}{*}{$\begin{array}{l}\mathrm{DBP}^{*} \\
\mathrm{mmHg}\end{array}$} & \multicolumn{2}{|c|}{ Initial drug therapy } \\
\hline & & & $\begin{array}{l}\text { without compelling } \\
\text { indication }\end{array}$ & $\begin{array}{l}\text { with compelling i } \\
\text { ndications }\end{array}$ \\
\hline Normal & $<120$ & and $<80$ & \multirow{2}{*}{$\begin{array}{c}\text { No antihypertensive } \\
\text { drug indicated }\end{array}$} & \multirow{2}{*}{$\begin{array}{l}\text { Drugs for compelling } \\
\text { indications }\end{array}$} \\
\hline Pre Hypertension & $120-139$ & or $80-89$ & & \\
\hline $\begin{array}{c}\text { Stage } 1 \\
\text { Hypertension }\end{array}$ & $140-159$ & or $90-99$ & $\begin{array}{l}\text { Consider ACEi/ARB, } \\
\text { CCB, Thiazide-type or } \\
\text { combination. }\end{array}$ & \multirow{2}{*}{$\begin{array}{c}\text { Drug(s) for compelling } \\
\text { indications. } \\
\text { Other antihypertensive } \\
\text { drugs: } \\
\text { diuretics, ACEI/ARB, } \\
\text { CCB, BB, aldosterone } \\
\text { antagonist, alpha- } \\
\text { blockers, direct renin } \\
\text { inhibitor. }\end{array}$} \\
\hline $\begin{array}{c}\text { Stage } 2 \\
\text { Hypertension }\end{array}$ & $\geq 160$ & or $\geq 100$ & $\begin{array}{l}\text { Two-drug combination } \\
\mathrm{ACE} / \mathrm{ARB}+\mathrm{CCB}^{* *} \text { or } \\
\text { Thiazide-type diuretic }\end{array}$ & \\
\hline
\end{tabular}

BP: Blood Pressure; SBP: Systolic Blood Pressure; DBP: Diastolic Blood Pressure; ACEi: Angiotensin Converting Enzyme inhibitor; BB: Beta-Blocker; ARB: Angiotensin Receptor Blocker; CCB: Calcium Channel Blocker.

*BP range based in patients with no cardiovascular risk factors or cardiovascular risk equivalents.

**The ACCOMPLISH trial showed that ACEi combined with a CCB was superior to ACEI and thiazide in non-obese patients.

Table 1: Classification of blood pressure.

$5 \mathrm{~min}$ ) and perform measurements 3 times, 2 minutes apart. Discard the first recording and take the average of the last two recordings as the BP for that time. Alterations in BP medications should be based on the average of the many recordings [9]. Never focus treatment on the highest or lowest recording. The average monthly value is the major consideration for medication adjustment.

\section{Non- pharmacological therapy}

Lifestyle Modifications should be recommended to all individuals for both prevention and as an integral part of hypertension management. Table 2 lists non-pharmacologic therapies that can have an adjunctive impact on BP control [4]. Even a few $\mathrm{mmHg}$ decreases in BP can improve both morbidity and mortality. Studies have demonstrated a significant reduction in SBP with weight loss, moderation in alcohol consumption, adoption of DASH diet (Dietary Approaches to Stop Hypertension) [10], low sodium intake (aim for less than $1500 \mathrm{mg} /$ day, but learn to accept $2000 \mathrm{mg} /$ day) and aerobic physical activity (150 minutes of moderate intensity activity/week) $[11,12]$. The DASH diet is based on an eating plan rich in fruits, vegetables, low-fat or non-fat dairy, whole grains, high fiber, with limited sugar-sweetened foods and beverages, red meat and added fats. Adoption of these measures reduces cardiovascular mortality alone and improves response to drug therapy. Achieving the desired sodium $(\mathrm{Na}+)$ restriction should decrease the SBP/diastolic(D) BP by about 3-4/2-3 $\mathrm{mmHg}[4,10]$. Important to note that a $\mathrm{Na}+$ intake of $>4 \mathrm{~g}$ /day reduces the anti-proteinuric effect of the renin-angiotensin-aldosterone system (RAAS) blockade by up to $50 \%$ [13]. The mechanism of an increased $\mathrm{Na}+$ intake on proteinuria is thought to be related to increased oxidant stress (partially) and an increase in the BP (partially) [14,15].

\section{Pharmacological therapy efficacy}

The effectiveness of antihypertensive agents is similar in lowering BP across different classes. Overall, adequate control is obtained in up to $50 \%$ of patients, with response rates to each class varying from patient to patient $[16,17]$. One of the significant beneficial effects of anti-hypertensive treatment is on decreasing the incidence of cardiovascular $(\mathrm{CV})$ complications, especially in those with moderate to severe hypertension (DBP 105-114 mmHg) [18]. It is estimated there can be a $20 \%$ CV benefit with lowering BP in this cohort. In contrast, the CV benefit from treatment in the mild to moderate hypertensive group is estimated to be $2 \%$ (from 17 trials involving approximately 48,000 patients) [19]. Patients who are over 60 years of age have an increased $\mathrm{CV}$ risk from $\mathrm{BP}$ elevation as compared to those with a similar BP who are less than this age. Therefore, treatment of BP in the elderly should be as aggressive as in younger individuals in an attempt to decrease complications [20].

The single most important determinant of reduction in cardiovascular risk is the amount of blood pressure reduction, as shown by several meta-analyses, including the American Heart Association (AHA) and the European Society of Hypertension (ESH) [11,16,21]. The BP goal in uncomplicated primary hypertension should be less than 140/90 [4]. Hypertensive patients with chronic kidney disease (with microalbuminuria or overt proteinuria) and/or diabetes (with microalbuminuria or overt proteinuria) should have a target blood pressure 120-130/70-80 mmHg [22]. This lower target should also be pursued in patients with known Coronary Artery Disease (CAD), or with CAD risk equivalents, such as carotid artery disease (carotid bruit, abnormal carotid ultrasound or angiography), peripheral arterial disease, abdominal aortic aneurysm or a 10-year Framingham risk score $\geq 10 \%$ [11]. This score, derived from the Framingham Heart Study, is used to estimate the 10-year risk of developing a heart attack in individuals aged 20 and older who do not have heart disease or diabetes. Variables include: age, gender, total cholesterol, HDL cholesterol, smoking status, SBP and current use of antihypertensives $[23,24]$.

\section{Choice of therapy}

The main classes of drugs used to treat hypertension are diuretics (Thiazides, loop and aldosterone antagonists), Angiotensin Converting Enzyme Inhibitors (ACEI), Angiotensin Receptor Blockers (ARB), Calcium Channel Blockers (CCB), Beta-Blockers (BB) and alphaadrenergic blockers. The alpha-adrenergic blockers and direct renin inhibitors are often $4^{\text {th }}$ or $5^{\text {th }}$ tier agents, added when less than optimal control is achieved with other medications. 
Citation: Riella C, Steinman TI (2013) Management of the Spectrum of Essential Hypertension: A 2013 Perspective. Cardiol Pharmacol 2: 111. doi:10.4172/23296607.1000112

\begin{tabular}{|c|c|}
\hline Modification & Approximate SBP reduction \\
\hline Weight reduction & $5-20 \mathrm{mmHg} / 10 \mathrm{~kg}$ weight loss \\
\hline DASH diet & $8-14 \mathrm{mmHg}$ \\
\hline Dietary sodium $\geq 2$ grams & $2-8 \mathrm{mmHg}$ \\
\hline Physical activity (aerobic) & $4-9 \mathrm{mmHg}$ \\
\hline & \\
\hline Reduction in alcohol consumption & $2-4 \mathrm{mmHg}$ \\
\hline
\end{tabular}

Table 2: Lifestyle Modifications

\section{Initial monotherapy-general concepts}

Single drug therapy in mild primary hypertension is effective in most patients. However, combination therapy may be required in patients with SBP in excess of $20 \mathrm{mmHg}$ and DBP above $10 \mathrm{mmHg}$ of the target range. For these patients combination therapy is indicated from the onset. Predictable differences in how each patient will respond to a given drug class have been observed. For example, African Americans often respond better to thiazide or CCB monotherapy as compared to ACEI or a $\mathrm{BB}$. Caucasians have better response rates to $\mathrm{BB}$ and $\mathrm{ACEI}$ and less to thiazides [25].

No consensus has been established on initial drug choice for every patient, and the most common therapeutic approach is trial and error. It is widely accepted that the amount of blood pressure reduction is the most important determinant in reduction of CV risk when there is no indication for a particular class of drugs $[11,17,26]$. Meta-analyses of all studies indicate that BP reduction is the major determinant of decreasing CV risk, not the choice of anti-hypertensive agent(s). In the following trials (ALLHAT, CAPPP, NORDIL, UKPDS, Stop Hypertension-2, CAMELOT) there was no difference in hard CV outcomes with different anti-hypertensive therapies [27-31].

In patients with compelling indications such as Ischemic Heart Disease (IHD), Chronic Kidney Disease (CKD) or stroke (CVA), some classes have shown greater benefits (Table 3). Patients with prior MI or heart failure have better outcomes with ACEI [11].

The optimal dosing across drug classes should start at half standard

\begin{tabular}{|c|c|}
\hline Compelling indication & Drug class indicated \\
\hline Heart failure (EF $\leq 40 \%)$ & $\begin{array}{c}\text { ACE inhibitor/ARB, BB, aldosterone } \\
\text { antagonist, diuretic }\end{array}$ \\
\hline Ischemic heart disease & $\begin{array}{c}\text { BB, ACE inhibitor, aldosterone antagonist } \\
\text { (post MI) }\end{array}$ \\
\hline Diabetes with proteinuria & ACE inhibitor/ARB \\
\hline Chronic kidney disease & ACE inhibitor/ARB \\
\hline Cerebrovascular disease & Thiazide, ACE inhibitor \\
\hline
\end{tabular}

Table 3: Drug choice based on Disease: Compelling indications.

doses. Increasing to a full standard or double the standard dose resulted in a small decrease in blood pressure values with a significant increase in both metabolic and symptomatic side effects [16,32]. Thiazide diuretics, $\mathrm{CCB}$ and $\mathrm{BB}$ were the main classes observed to have significant increase in adverse effects with higher doses. ACEI and ARB had a lower rate of side effects and no dose dependence was observed [16]. Therefore, dose titration up to a single step is generally recommended, the next step being adding another drug class at half the standard recommended maintenance dose.

\section{Monotherapy guidelines}

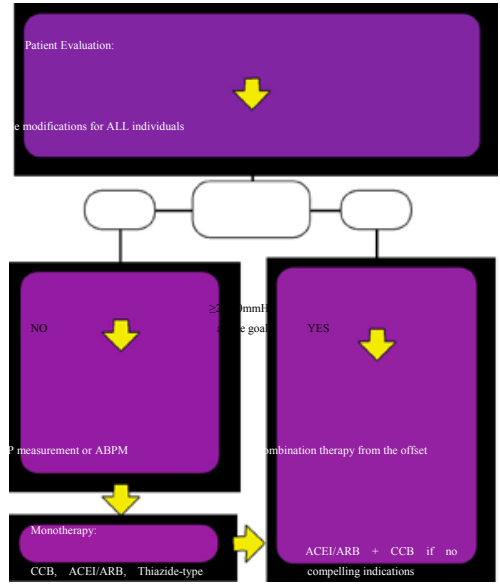

BP: Blood Pressure; ABPM: Ambulatory Blood Pressure Monitoring; ACEI: Angiotensin Converting Enzyme Inhibitor; ARB: Angiotensin Receptor Blocker; CCB: Calcium Channel Blocker (dihydropyridine-type).

*The thiazide-type diuretic of choice is Chlorthalidone

Figure 1: Algorithm for the treatment of hypertension

The 2011 NICE guidelines recommends, if there is no indication for a specific class of drugs, CCB or ACEI/ARB as first line therapy [9]. ACEI/ ARB for individuals under the age of 55 and CCB for individuals aged 55 and older or African Americans of any age. Table 4 shows, in order, the NICE recommendations of a CCB, ACEI or ARB, thiazidetype diuretic, $\mathrm{BB}$, alpha-adrenergic blocker being added in sequential order to achieve the target $\mathrm{BP}$.

\section{Diuretics}

A thiazide-type diuretic is indicated if a CCB is not tolerated (lower extremity edema) or if there is evidence of heart failure (given $\mathrm{EF}>40 \%$ ) or at high risk of developing heart failure. The drug of choice for this class is chlorthalidone.

Lessons learned from large-scale anti-hypertensive trials guide current day treatment. For example, the ALLHAT study (involved over 41,000 patients) demonstrated benefit with lower rates of heart failure and better blood pressure control with chlorthalidone as compared to $\mathrm{CCB}$ and ACEI in patients with at least one coronary risk factor (with similar primary outcomes across all classes of agents) [27].

When compared to hydrochlorothiazide (HCTZ), chlorthalidone is 1.5 to 2 times as potent and has a longer duration of action (2472 hours vs. $6-12$ hours) [33,34]. The recommended starting dose is $12.5 \mathrm{mg}$ daily, titrated up to $25 \mathrm{mg}$ daily. Concerns with the use of chlorthalidone are the metabolic adverse effects, namely hypokalemia, glucose intolerance and hyperuricemia (the same exists for HCTZ). Hypokalemia occurred in up to $8 \%$ of treated patients within the first 1-2 weeks [35]. When a mean BP baseline of 146/84 was noted in the ALLHAT trial, combination therapy was required in $30 \%$ of patients at one year and $40 \%$ at four years. As already stated, the choice of antihypertensive agent does not predict outcomes. At years one and two of treatment with chlorthalidone the mean SBP decrease was $3.7 \mathrm{mmHg}$. In contrast, HCTZ led to a $2.8 \mathrm{mmHg}$ SBP lowering in the same time frame [27].

In both the ALLHAT and SHEP trials, low dose chlorthalidone (12.5-25 mg/day) was more efficacious than HCTZ in reducing all CV events for up to 5 years, including Congestive Heart Failure (CHF). This finding was independent of the attained BP [27,36]. A recent 
Citation: Riella C, Steinman TI (2013) Management of the Spectrum of Essential Hypertension: A 2013 Perspective. Cardiol Pharmacol 2: 111. doi:10.4172/23296607.1000112

observational cohort study of over 10,000 individuals compared primary and safety outcomes in patients treated with chlorthalidone versus HCTZ [37]. CV events or death were similar between the two groups with a higher incidence of electrolyte abnormalities with chlorthalidone, particularly hypokalemia. Both groups were matched to sex, year of treatment initiation, and propensity score. It is important to mention that no adjustment was made to the difference in potency between each drug. Doses of $12.5 \mathrm{mg}, 25 \mathrm{mg}$ and $50 \mathrm{mg}$ oral daily (HCTZ and chlorthalidone) were compared as being equipotent.

\section{Predictors of lack of BP control in the ALLHAT study (in descending order) [27]: \\ - $\quad$ Older age \\ - Obesity \\ - $\quad$ Female \\ - Initial SBP \\ - $\quad$ Chronic kidney disease \\ - Left ventricular hypertrophy \\ - $\quad$ Black race}

\section{Angiotensin Converting Enzyme Inhibitors (ACEI)}

ACEI are the drug of choice for individuals younger than 55 and with no compelling indications for other drug class (NICE guidelines) [9]. ACEI are also considered standard of care in patients with heart failure and systolic dysfunction ( $\mathrm{EF} \leq 40 \%)$, post myocardial infarction, proteinuric CKD and diabetes $[11,38,39]$. It is important to reiterate the importance of obtaining a lower blood pressure goal in this group of patients, $\leq 130 / 80 \mathrm{mmHg}[4,40]$.

\section{Angiotensin Receptor Blockers (ARB)}

Generally, similar indications as compared to ACEI. They are appropriate in patients with $\mathrm{CV}$ disease who are intolerant to ACE inhibitors (cough being the major side effect from ACEI that leads to stopping this agent). ARB have shown to reduce incidence of cerebrovascular events, kidney disease and Ischemic Heart Disease (IHD) events [41]. The ONTARGET study compared telmisartan (ARB) and ramipril (ACEI) head-to-head and in combination in patients with vascular disease (known CAD or CAD equivalent) or diabetes with end-organ damage. Telmisartan was equivalent to ramipril in reducing primary outcomes with less angioedema. The combination arm had more adverse events without an increase in benefit [42].

\section{Calcium channel blockers (CCB)}

$\mathrm{CCB}$ are first line therapy in individuals over the age of 55 or in African American patients of any age (NICE guidelines) [9]. CCB confer similar BP lowering properties with distinct actions on cardiac contractility and conduction. The dihydropyridines are long-acting agents, the most common drugs being amlodipine and nifedipine. The non-dihydropyridine class possesses additional chronotropic effects and can be used for rate control in atrial fibrillation and angina pectoris. Non-dihydropyridines are contra-indicated in patients with heart failure with left ventricular systolic dysfunction [43].

\section{Beta-Blockers (BB)}

Beta-Blockers are considered standard of care post Myocardial
Infarction (MI), in left ventricular dysfunction with or without symptoms of heart failure and in patients with angina pectoris [17]. Cardiovascular protection has not been demonstrated in patients without symptomatic $\mathrm{CAD}$, no history of $\mathrm{MI}$ or without heart failure [44]. In patients over 60 and no risk factors, an increase in CV risk was observed, particularly stroke [45].

\section{Aldosterone antagonists}

Spironolactone and eplerenone reduce blood pressure and confer cardioprotective effect in patients with heart failure (ejection fraction $\leq 40 \%)$ when combined with an anti-heart failure regimen (BB, ACE inhibitor and diuretic) [46]. No major study has analyzed CV outcomes in those treated for hypertension without left ventricular dysfunction.

\section{Alpha- adrenergic blockers}

There is no indication for monotherapy of primary hypertension with alpha-blockers. The ALLHAT trial showed an increased risk of heart failure and rate of $\mathrm{CV}$ events when compared to chlorthalidone alone in patients with hypertension [27].

\section{Direct renin inhibitors}

Aliskiren was the first oral direct rennin inhibitor to become available. It has shown BP lowering effect comparable to other classes [47]. Patients intolerant to ACEI/ARB may benefit from Aliskiren, especially if anti-proteinuric effect is desired. It should not be used in pregnancy or in combination with ACEI or ARB (see Combination Therapy section).

\section{Combination therapy}

Combination therapy should be considered from the beginning in individuals with blood pressures that exceed $20 / 10 \mathrm{mmHg}$ above set target range. In patients with mild primary hypertension undergoing monotherapy, with inadequate blood pressure control, stepwise monotherapy may be attempted prior to adding another drug. Up to $50 \%$ of individuals are likely to have adequate blood pressure control with the stepwise monotherapy approach $[48,49]$. Combination treatment can follow if there is a failure of stepwise monotherapy.

Several large trials have helped guide an evidence-based approach to treatment. The ACCOMPLISH trial (emphasizing combination therapy) noted when the mean baseline BP was $145 / 80$ or greater in patients at high risk for a CV event, benazepril in combination with amlodipine produced better end results as compared to a combination of benazepril with HCTZ [50]. Significant reductions in the primary composite endpoint of fatal or non-fatal $\mathrm{CV}$ event and secondary endpoint of CV death, non-fatal MI or stroke were noted. Lower rates of adverse events were documented in the benazepril-amlodipine combination, and benefits were independent of the achieved BP lowering [50]. If there is no compelling indication for a particular drug class, the combination of ACEI and a dihydropyridine CCB should be used instead of a combination of ACEI and thiazide, particularly in the non-obese individual [50,51].

Other trials have supported combination therapy to achieve various endpoints. The ACCORD trial in type 2 diabetics showed a lower incidence of strokes with intensive treatment to lower the BP, but there was no difference in coronary events [52]. The HOPE trial addressed the timing of combination anti-hypertensive therapy [53]. ACEI before sleep reduced the incidence of combined CV death, MI and stroke. Bedtime dosing of at least one anti-hypertensive agent should be tried when the BP does not fall by at least $10 \%$ during sleep 
Citation: Riella C, Steinman TI (2013) Management of the Spectrum of Essential Hypertension: A 2013 Perspective. Cardiol Pharmacol 2: 111. doi:10.4172/23296607.1000112

(non-dipping) [53]. Non-dipping is a stronger predictor of adverse CV outcomes and evening dosing of at least one anti-hypertensive drug that is not a diuretic can restore dipping. VALUE, ASCOT and the BPLA trials noted better outcomes with amlodipine as compared to valsartan or atenolol, but differences were no longer significant when adjusted for differences in attained BP $[54,55]$.

In addition to a decrease in the incidence of $\mathrm{CV}$ events, a decrease in the development of CKD was also noted with combination therapy [56]. In this particular study, benazepril 20mg (starting dose) daily was the ACEI utilized in combination with either amlodipine $5 \mathrm{mg}$ daily (starting dose) or HCTZ $12.5 \mathrm{mg}$ daily. Individuals with compelling indications for a $\mathrm{BB}$ utilized a combination of $\mathrm{CCB}$ or thiazide. Alpha-blockers can be added to combination therapy in patients with symptomatic benign prostatic hyperplasia. A recent study found that a three-drug combination of ARB, CCB and HCTZ was more effective in achieving $\mathrm{BP}$ control when compared to a two-drug combination of the given classes (ARB/CCB, ARB/HCTZ, CCB/HCTZ). The regimen was well tolerated and effective in both elderly $(\geq 65)$ and non-elderly $(<65)$ groups [57].

The role for oral direct renin inhibitors (aliskiren) is yet to be determined. It has been shown to lower BP comparably to other drug classes and to reduce proteinuria when used in combination with losartan. The AVOID trial assessed this combination in patients with hypertension, type 2 diabetes and albuminuria [58]. The combination therapy was associated with $20 \%$ greater reduction in the albuminto-creatinine ratio as compared to losartan alone, independent of $\mathrm{BP}$ reduction. Clinical benefits of this reduction were not measured in this study. A higher rate of adverse events such as hyperkalemia, hypotension and non-fatal stroke were observed in the ALTITUDE trial (ACEI or ARB in combination with aliskiren) [59].

\section{Isolated Systolic Hypertension (ISH)}

ISH is defined as SBP $\geq 140 \mathrm{mmHg}$ with a $\mathrm{DBP}<90 \mathrm{mmHg}$, and this scenario is invariably noted in the elderly. Goals of therapy, as documented in the following trials (SHEP, Syst-EVR, MRC, HYVET) are a SBP $<140 \mathrm{mmHg}$ and no side effects from the medications employed $[20,36,60,61]$. Another target of treatment if the initial SBP is $\geq 180 \mathrm{mmHg}$ is a reduction to $<160 \mathrm{mmHg}$. Aim for a SBP that is $20 \mathrm{mmHg}$ below the initial SBP of $160-180 \mathrm{mmHg}$. The HYVET study provided evidence that treatment of hypertension in patients greater than 80 years of age or older with indapamide (sustained release), with or without perindopril, is beneficial [20].

\section{Resistant hypertension}

The definition is that the BP remains above target goal in spite of 3 concurrent anti-hypertensive agents of different classes at optimal doses, one drug being a diuretic. By this definition, $12.8 \%$ of treated hypertensive patients have resistant hypertension from NHANES data [62]. In the ASCOT study, $49 \%$ were diagnosed as having resistant hypertension during a median follow up of 4.8 years [63]. 25-28\% of all patients in the accomplish trial remained with uncontrolled BP after a follow up of 3 years [50]. An elevated heart rate, especially after BB therapy, suggests a possible heightened sympathetic tone. New interventional advances in the treatment of resistant hypertension are based on the supposition that the nerves leading in and out of the kidney play a central role in Sympathetic Nervous System (SNS) hyperactivation. Percutaneous transluminal ablation of the renal nerves, also known as Renal Denervation (RDN), is a developing novel therapeutic option for the treatment of resistant hypertension. Radio frequency ablation (RDN) reduces the drive of the SNS, which is central to BP regulation. By denervation of the renal sympathetic nerves encircling the renal arteries, achieved by a proprietary generator and flexible catheter introduced into each renal artery, the output of the sympathetic nerves located outside the renal artery walls can be modulated [64]. Two RDN trials in Europe and Australia demonstrated the drop in SBP and DBP as charted below in a cohort with a baseline BP $178 / 97 \mathrm{mmHg}$, while on an average of 5.2 anti-hypertensive agents $[65,66]$.

\section{Fall in SBP/DBP (mmHg) after Treatment with RDN}

1 month $20 / 7$

3 months $24 / 8$

6 months $32 / 12$

Glucose, fasting insulin levels and C-peptide levels fell co-incident with the drop in BP. Another observation was that sleep apnea improved after RDN [66]. There is now an ongoing multi-center RDN trial in the United States (the Symplicity HTN-3 Trial).

\section{Conclusion}

Considerable improvements in awareness, detection and treatment of hypertension have been made in the past decade. New techniques and genetics advance the field and provide us with new tools to treat and detect individuals at risk. Despite these advancements, the management of hypertension continues to be challenging with only half of the affected population having adequate BP control. Considering the impact that adequate treatment can make in preventing deaths, there is a constant challenge to improve care of patients with hypertension.

\section{References}

1. Fryar CD, Hirsch R, Eberhardt MS, Yoon SS, Wright JD (2010) Hypertension, high serum total cholesterol, and diabetes: racial and ethnic prevalence differences in U.S. adults, 1999-2006. NCHS Data Brief : 1-8.

2. Yoon SS, Burt V, Louis T, Carroll MD (2012) Hypertension among adults in the United States, 2009-2010. NCHS Data Brief : 1-8.

3. Farley TA, Dalal MA, Mostashari F, Frieden TR (2010) Deaths preventable in the U.S. by improvements in use of clinical preventive services. Am J Prev Med 38: $600-609$.

4. Chobanian AV, Bakris GL, Black HR, Cushman WC, Green LA, et al. (2003) The Seventh Report of the Joint National Committee on Prevention, Detection, Evaluation, and Treatment of High Blood Pressure: the JNC 7 report. JAMA 289: $2560-2572$.

5. Coresh J, Wei GL, McQuillan G, Brancati FL, Levey AS, et al. (2001) Prevalence of high blood pressure and elevated serum creatinine level in the United States: findings from the third National Health and Nutrition Examination Survey (19881994). Arch Intern Med 161: 1207-1216.

6. Hsu CY, McCulloch CE, Darbinian J, Go AS, Iribarren C (2005) Elevated blood pressure and risk of end-stage renal disease in subjects without baseline kidney disease. Arch Intern Med 165: 923-928.

7. Wilson PW (1994) Established risk factors and coronary artery disease: the Framingham Study. Am J Hypertens 7: 7S-12S.

8. Vasan RS, Larson MG, Leip EP, Kannel WB, Levy D (2001) Assessment of frequency of progression to hypertension in non-hypertensive participants in the Framingham Heart Study: a cohort study. Lancet 358: 1682-1686.

9. Ritchie LD, Campbell NC, Murchie P (2011) New NICE guidelines for hypertension. BMJ 343: d5644.

10. Svetkey LP, Simons-Morton DG, Proschan MA, Sacks FM, Conlin PR, et al. (2004) Effect of the dietary approaches to stop hypertension diet and reduced sodium intake on blood pressure control. J Clin Hypertens (Greenwich) 6: 373381.

11. Rosendorff C, Black HR, Cannon CP, Gersh BJ, Gore J, et al. (2007) Treatment of hypertension in the prevention and management of ischemic heart disease: a scientific statement from the American Heart Association Council for High 
Citation: Riella C, Steinman TI (2013) Management of the Spectrum of Essential Hypertension: A 2013 Perspective. Cardiol Pharmacol 2: 111. doi:10.4172/23296607.1000112

Blood Pressure Research and the Councils on Clinical Cardiology and Epidemiology and Prevention. Circulation 115: 2761-2788.

12. Elmer PJ, Obarzanek E, Vollmer WM, Simons-Morton D, Stevens VJ, et al. (2006) Effects of comprehensive lifestyle modification on diet, weight, physical fitness, and blood pressure control: 18-month results of a randomized trial. Ann Intern Med 144: 485-495.

13. Heeg JE, de Jong PE, van der Hem GK, de Zeeuw D (1989) Efficacy and variability of the antiproteinuric effect of ACE inhibition by lisinopril. Kidney Int 36: 272-279.

14. Mishra SI, Jones-Burton C, Fink JC, Brown J, Bakris GL, et al. (2005) Does dietary salt increase the risk for progression of kidney disease? Curr Hypertens Rep 7: 385-391.

15. Laffer CL, Bolterman RJ, Romero JC, Elijovich F (2006) Effect of salt on isoprostanes in salt-sensitive essential hypertension. Hypertension 47: 434440 .

16. Law MR, Morris JK, Wald NJ (2009) Use of blood pressure lowering drugs in the prevention of cardiovascular disease: meta-analysis of 147 randomised trials in the context of expectations from prospective epidemiological studies. BMJ 338: b1665

17. Wang JG, Staessen J (2003) Benefits of antihypertensive pharmacologic therapy and blood pressure reduction in outcome trials. J Clin Hypertens (Greenwich) 5: 66-75.

18. (1970) Effects of treatment on morbidity in hypertension. II. Results in patients with diastolic blood pressure averaging 90 through $114 \mathrm{~mm} \mathrm{Hg}$. JAMA 213: $1143-1152$.

19. Hebert PR, Moser M, Mayer J, Glynn RJ, Hennekens CH (1993) Recent evidence on drug therapy of mild to moderate hypertension and decreased risk of coronary heart disease. Arch Intern Med 153: 578-581.

20. Beckett NS, Peters R, Fletcher AE, Staessen JA, Liu L, et al. (2008) Treatment of hypertension in patients 80 years of age or older. N Engl J Med 358: 1887 1898.

21. Mancia G, De Backer G, Dominiczak A, Cifkova R, Fagard R, et al. (2007) 2007 Guidelines for the management of arterial hypertension: The Task Force for the Management of Arterial Hypertension of the European Society of Hypertension (ESH) and of the European Society of Cardiology (ESC). Eur Heart J 28: 14621536.

22. (2012) Kidney Disease: Improving Global Outcomes (KDIGO) Blood Pressure Work Group. KDIGO Clinical Practice Guideline for the Management of Blood Pressure in Chronic Kidney Disease. Kidney International Supplements 2: 337414.

23. National Cholesterol Education Program (NCEP) Expert Panel on Detection, Evaluation, and Treatment of High Blood Cholesterol in Adults (Adult Treatment Panel III) (2002) Third Report of the National Cholesterol Education Program (NCEP) Expert Panel on Detection, Evaluation, and Treatment of High Blood Cholesterol in Adults (Adult Treatment Panel III) final report. Circulation 106: 3143-3421.

24. Wilson PW, D’Agostino RB, Levy D, Belanger AM, Silbershatz H, et al. (1998) Prediction of coronary heart disease using risk factor categories. Circulation 97: 1837-1847.

25. Materson BJ, Reda DJ, Cushman WC, Massie BM, Freis ED, et al. (1993) Singledrug therapy for hypertension in men. A comparison of six antihypertensive agents with placebo. The Department of Veterans Affairs Cooperative Study Group on Antihypertensive Agents. N Engl J Med 328: 914-921.

26. Staessen JA, Wang JG, Thijs L (2003) Cardiovascular prevention and blood pressure reduction: a quantitative overview updated until 1 March 2003 . J Hypertens 21: 1055-1076.

27. ALLHAT Officers and Coordinators for the ALLHAT Collaborative Research Group The Antihypertensive and Lipid-Lowering Treatment to Prevent Heart Attack Trial. (2002) Major outcomes in high-risk hypertensive patients randomized to angiotensin-converting enzyme inhibitor or calcium channel blocker vs diuretic: The Antihypertensive and Lipid-Lowering Treatment to Prevent Heart Attack Trial (ALLHAT). JAMA 288: 2981-2997.

28. Scheen AJ (1999) CAPPP trial. Captopril Prevention Project. Lancet 353: 1793-1794.

29. King P, Peacock I, Donnelly R (1999) The UK prospective diabetes study (UKPDS): clinical and therapeutic implications for type 2 diabetes. $\mathrm{Br} \mathrm{J} \mathrm{Clin}$ Pharmacol 48: 643-648.
30. Nissen SE, Tuzcu EM, Libby P, Thompson PD, Ghali M, et al. (2004) Effect of antihypertensive agents on cardiovascular events in patients with coronary disease and normal blood pressure: the CAMELOT study: a randomized controlled trial. JAMA 292: 2217-2225.

31. Lindholm LH, Hansson L, Dahlof B, Ekbom T, Hedner T, et al. (1996) The Swedish Trial in old patients with hypertension-2 (STOP-hypertension-2): a progress report. Blood Press 5: 300-304.

32. Kaplan NM (1992) The appropriate goals of antihypertensive therapy: neither too much nor too little. Ann Intern Med 116: 686-690.

33. Carter BL, Ernst ME, Cohen JD (2004) Hydrochlorothiazide versus chlorthalidone: evidence supporting their interchangeability. Hypertension 43 : $4-9$

34. Ernst ME, Carter BL, Goerdt CJ, Steffensmeier JJ, Phillips BB, et al. (2006) Comparative antihypertensive effects of hydrochlorothiazide and chlorthalidone on ambulatory and office blood pressure. Hypertension 47: 352-358.

35. Carlsen JE, KÃ ber L, Torp-Pedersen C, Johansen P (1990) Relation between dose of bendrofluazide, antihypertensive effect, and adverse biochemical effects. BMJ 300: 975-978.

36. Petrovitch H, Vogt TM, Berge KG (1992) Isolated systolic hypertension: lowering the risk of stroke in older patients. SHEP Cooperative Research Group. Geriatrics 47: 30-32, 35-8.

37. Dhalla IA, Gomes T, Yao Z, Nagge J, Persaud N, et al. (2013) Chlorthalidone versus hydrochlorothiazide for the treatment of hypertension in older adults: a population-based cohort study. Ann Intern Med 158: 447-455.

38. (1987) Effects of enalapril on mortality in severe congestive heart failure Results of the Cooperative North Scandinavian Enalapril Survival Study (CONSENSUS). The CONSENSUS Trial Study Group. N Engl J Med 316: 1429-1435.

39. (1992) Effect of enalapril on mortality and the development of heart failure in asymptomatic patients with reduced left ventricular ejection fractions. The SOLVD Investigattors. N Engl J Med 327: 685-691.

40. European Society of Hypertension-European Society of Cardiology Guidelines Committee (2003) 2003 European Society of Hypertension-European Society of Cardiology guidelines for the management of arterial hypertension. J Hypertens 21: 1011-1053.

41. Pfeffer MA, McMurray JJ, Velazquez EJ, Rouleau JL, KA, ber L, et al. (2003) Valsartan, captopril, or both in myocardial infarction complicated by heart failure, left ventricular dysfunction, or both. N Engl J Med 349: 1893-1906.

42. ONTARGET Investigators, Yusuf S, Teo KK, Pogue J, Dyal L, et al. (2008) Telmisartan, ramipril, or both in patients at high risk for vascular events. N Engl J Med 358: 1547-1559.

43. Goldstein RE, Boccuzzi SJ, Cruess D, Nattel S (1991) Diltiazem increases late-onset congestive heart failure in postinfarction patients with early reduction in ejection fraction. The Adverse Experience Committee; and the Multicenter Diltiazem Postinfarction Research Group. Circulation 83: 52-60.

44. Messerli FH, Grossman E, Goldbourt U (1998) Are beta-blockers efficacious as first-line therapy for hypertension in the elderly? A systematic review. JAMA 279: 1903-1907.

45. Khan N, McAlister FA (2006) Re-examining the efficacy of beta-blockers for the treatment of hypertension: a meta-analysis. CMAJ 174: 1737-1742.

46. Pitt B, Zannad F, Remme WJ, Cody R, Castaigne A, et al. (1999) The effect of spironolactone on morbidity and mortality in patients with severe heart failure. Randomized Aldactone Evaluation Study Investigators. N Engl J Med 341: 709717.

47. Oh BH, Mitchell J, Herron JR, Chung J, Khan M, et al. (2007) Aliskiren, an ora renin inhibitor, provides dose-dependent efficacy and sustained 24-hour blood pressure control in patients with hypertension. J Am Coll Cardiol 49: 11571163.

48. Materson BJ, Reda DJ, Preston RA, Cushman WC, Massie BM, et al. (1995) Response to a second single antihypertensive agent used as monotherapy for hypertension after failure of the initial drug. Department of Veterans Affairs Cooperative Study Group on Antihypertensive Agents. Arch Intern Med 155 1757-1762.

49. Dickerson JE, Hingorani AD, Ashby MJ, Palmer CR, Brown MJ (1999) Optimisation of antihypertensive treatment by crossover rotation of four major classes. Lancet 353: 2008-2013. 
Citation: Riella C, Steinman TI (2013) Management of the Spectrum of Essential Hypertension: A 2013 Perspective. Cardiol Pharmacol 2: 111. doi:10.4172/23296607.1000112

50. Jamerson K, Weber MA, Bakris GL, Dahlof B, Pitt B, et al. (2008) Benazepril plus amlodipine or hydrochlorothiazide for hypertension in high-risk patients. $N$ Engl J Med 359: 2417-2428.

51. Weber MA, Jamerson K, Bakris GL, Weir MR, Zappe D, et al. (2013) Effects of body size and hypertension treatments on cardiovascular event rates: subanalysis of the ACCOMPLISH randomised controlled trial. Lancet 381: 537545

52. ACCORD Study Group, Cushman WC, Evans GW, Byington RP, Goff DC Jr, et al. (2010) Effects of intensive blood-pressure control in type 2 diabetes mellitus. N Engl J Med 362: 1575-1585.

53. Yusuf S, Sleight P, Pogue J, Bosch J, Davies R, et al. (2000) Effects of an angiotensin-converting-enzyme inhibitor, ramipril, on cardiovascular events in high-risk patients. The Heart Outcomes Prevention Evaluation Study Investigators. N Engl J Med 342: 145-153.

54. Julius S, Kjeldsen SE, Weber M, Brunner HR, Ekman S, et al. (2004) Outcomes in hypertensive patients at high cardiovascular risk treated with regimens based on valsartan or amlodipine: the VALUE randomised trial. Lancet 363 2022-2031.

55. Meurin P (2006) The ASCOT trial: clarifying the role of ACE inhibition in the reduction of cardiovascular events in patients with hypertension. Am J Cardiovasc Drugs 6: 327-334.

56. Bakris GL, Sarafidis PA, Weir MR, DahlÃ If B, Pitt B, et al. (2010) Renal outcomes with different fixed-dose combination therapies in patients with hypertension at high risk for cardiovascular events (ACCOMPLISH): a prespecified secondary analysis of a randomised controlled trial. Lancet 375: 1173-1181.

57. Lewin AJ, Izzo JL Jr, Melino M, Lee J, Fernandez V, et al. (2013) Combined Olmesartan, Amlodipine, and Hydrochlorothiazide Therapy in Randomized Patients with Hypertension: A Subgroup Analysis of the TRINITY Study by Age. Drugs Aging 30: 549-560.
58. Parving HH, Persson F, Lewis JB, Lewis EJ, Hollenberg NK; AVOID Study Investigators (2008) Aliskiren combined with losartan in type 2 diabetes and nephropathy. N Engl J Med 358: 2433-2446.

59. Parving HH, Brenner BM, McMurray JJ, de Zeeuw D, Haffner SM, et al. (2012) Cardiorenal end points in a trial of aliskiren for type 2 diabetes. $\mathrm{N}$ Engl $\mathrm{J}$ Med 367: 2204-2213.

60. Staessen JA, Fagard R, Thijs L, Celis H, Arabidze GG, et al. (1997) Randomised double-blind comparison of placebo and active treatment for older patients with isolated systolic hypertension. The Systolic Hypertension in Europe (Syst-Eur) Trial Investigators. Lancet 350: 757-764.

61. (1992) Medical Research Council trial of treatment of hypertension in older adults: principal results. MRC Working Party. BMJ 304: 405-412.

62. Persell SD (2011) Prevalence of resistant hypertension in the United States, 2003-2008. Hypertension 57: 1076-1080.

63. Dahlof B, Sever PS, Poulter NR, Wedel H, Beevers DG, et al. (2005) Prevention of cardiovascular events with an antihypertensive regimen of amlodipine adding perindopril as required versus atenolol adding bendroflumethiazide as required, in the Anglo-Scandinavian Cardiac Outcomes Trial-Blood Pressure Lowering Arm (ASCOT-BPLA): a multicentre randomised controlled trial. Lancet 366: 895-906.

64. DiBona GF, Esler M (2010) Translational medicine: the antihypertensive effect of renal denervation. Am J Physiol Regul Integr Comp Physiol 298: R245-R253.

65. Esler MD, Krum H, Sobotka PA, Schlaich MP, Schmieder RE, et al. (2010) Rena sympathetic denervation in patients with treatment-resistant hypertension (The Symplicity HTN-2 Trial): a randomised controlled trial. Lancet 376: 1903-1909.

66. Witkowski A, Prejbisz A, Florczak E, Kadziela J, Sliwinski P, et al. (2011) Effects of renal sympathetic denervation on blood pressure, sleep apnea course, and glycemic control in patients with resistant hypertension and sleep apnea. Hypertension 58: 559-565. 